\title{
The 7th Italian supplement: a selection from the Italian Spine Society and Scoliosis Study Group (SICV\&GIS)
}

\author{
Marco Crostelli ${ }^{1}$
}

Received: 8 September 2017 / Accepted: 10 September 2017 / Published online: 14 October 2017

(c) Springer-Verlag GmbH Germany 2017

Since its foundation 40 year ago, in 1977, the Italian Scoliosis Study Group (Gruppo Italiano Scoliosi-GIS) has hosted and promoted studies and researches on any aspect of the diseases of the spine.

Given the progressive and increased interest in the different spinal pathologies, overcoming the exclusive initial interest in spinal deformity, the Society has been renamed in 2012 as "Italian Spine Society and Italian Scoliosis Study Group" (Società Italiana di Chirurgia Vertebrale e Gruppo Italiano Scoliosi; SICV\&GIS), thus progressively including other disciplines other than orthopedics, mainly by the implementation of Neurosurgeons into the Society, improving the chance of discussion on the spinal topics between the members.

The history of the spine surgery in Italy is full of examples of research and innovation of the highest quality performed by surgeons of fame, that already in the 70s, have developed surgical techniques and classifications of spinal diseases which are still valid and kept in mind by spinal surgeons. Citing all the names of surgeons that gave shine to the Italian spine surgery is out of the scope of this introduction, and I would only cite three surgeons as an example: E. Ascani (Scheuermann Disease and growing rods); P.G. Marchetti (end-fusion vertebrae and spondylolisthesis); A. Ponte (Ponte osteotomy); they were all founders of the Society, and their work and experience is still today cited in papers and presentations.

Marco Crostelli

marco.crostelli@opbg.net

1 SICV-GIS Italian Spine and Scoliosis Society, Spine Surgery Unit, Ospedale Pediatrico Bambino Gesù, Piazza Sant'Onofrio 4, 00164 Rome, Italy
However, the difficulty to have access to the studies and experiences of the Italian surgeons is evident by the confrontation with foreign colleagues. Their contributions were mainly presented at the Annual Congress of the Society, and were published in Italian by the former official journal of the Society, named "Progresses in Spinal Diseases" (Progressi in Patologia Vertebrale): this made it difficult to find and study the manuscripts. For these reasons, I would like to thank Max Aebi once more. While being Editor-in-Chief of European Spine Journal in the past, which is recognized worldwide as one of the main journals in the field of spinal diseases, he stimulated and promoted the participation of our Society to the Journal by submitting manuscripts; moreover, he promoted the realization of a special issue with selected studies presented at the National Congress of the Society, and later on an issue with the best of the Italian scientific production in this field.

As President of the SICV\&GIS, I am therefore proud to present the manuscripts selected between some of those presented at our Annual Meeting, as well as selected studies submitted by Society Members. With regret, these represent only a small part of what has been produced this year by our colleagues. However, I do trust that these might mirror the quality of the scientific production of a society, whose main aim is to grow continuously by an internal dialectic discussion, and by the confrontation with international colleagues from all over the world.

Compliance with ethical standards

Conflict of interest Author declare that he has no conflict of interest. 